\title{
RESEARCH
}

Open Access

\section{Treatment satisfaction and adherence to medications among multiple sclerosis patients in Saudi Arabia}

Adel Alhazzani ${ }^{1 *}$ (D) Mohammed Alqahtani ${ }^{2}$, Noof Alamri ${ }^{3}$, Leen Sarhan ${ }^{4}$, Shahad Alkhashrami ${ }^{4}$ and Mohammed Alahmarii ${ }^{2}$

\begin{abstract}
Background: Despite the apparent benefits of disease-modifying drug (DMD) use among multiple sclerosis (MS) patients, their rates of adherence are often variable and in some cases are quite low.

Aim of the study: To assess medication adherence and its relationship with treatment satisfaction of MS patients in Saudi Arabia

Patients and methods: Following a cross-sectional design, 598 adult MS patients were recruited from all tertiary care hospitals in all regions of Saudi Arabia. Patients' medication adherence was assessed using the Arabic version of the eight-item Morisky Medication Adherence Scale (MMAS-8). Treatment satisfaction was assessed using the Treatment Satisfaction Questionnaire for Medication. Disease severity was assessed using the Patient-Determined Disease Steps (PDDS).
\end{abstract}

Results: The most used drug was interferon beta-1b (24.1\%), while 18.7\% were using interferon beta-1a and $17.4 \%$ were using fingolimod. Patients' mean PDDS was $2.8 \pm 1.9$. Only 9.7\% were "adherent" to medication. Patients' adherence differed according to their educational level $(p<0.001)$, their currently received medications $(p=0.032)$, with those on Fingolimod having the highest adherence (17.3\%). Treatment satisfaction was significantly higher among adherent patients $(p<0.023)$. The main reasons for changing prescribed drugs were the presence of attacks, i.e., response to treatment was substandard (41.8\%) and the experienced side effects of used drugs (39.9\%). PDDS differed significantly according to patients' treatment adherence only among those receiving interferon beta$1 \mathrm{~b}$, with higher mean severity score among those who were adherent $(p=0.002)$.

Conclusions: Medication adherence among MS patients in Saudi Arabia is low. Higher adherence is associated with patients' higher education. The main underlying reasons for changing prescribed drugs are the presence of attacks, substandard response to treatment, or suffering the DMDs' side effects. Medication adherence is associated with higher treatment satisfaction.

Keywords: Multiple sclerosis, Disease-modifying drugs, Medication adherence, Treatment satisfaction, Disease severity

\footnotetext{
*Correspondence: alhazzani@kku.edu.sa

${ }^{1}$ Neurology Section, Department of Medicine, King Saud University, P.O. Box

641, Riyadh, Saudi Arabia

Full list of author information is available at the end of the article
} 


\section{Introduction}

Multiple sclerosis (MS) is a chronic autoimmune degenerative disorder of the central nervous system affecting about 2.5 million individuals worldwide [1]. Despite there is no known cure, several immune modulatory drugs have been used for the treatment of MS. These drugs include the injectable medications which are interferon beta-1b subcutaneous, interferon beta-1a subcutaneous, glatiramer acetate subcutaneous, interferon beta1a intramuscular, and peg interferon beta-1a intramuscular, while the oral medications are fingolimod, teriflunomide, dimethyl fumarate, cladribine, and siponimod. The infused medications are natalizumab, alemtuzumab, ocrelizumab, and mitoxantrone.

Spessotto et al. stated that treatment of MS is longterm and outcomes are more qualitative than quantitative. Therefore, it is particularly important to know how patients feel about disease-modifying drugs (DMDs) that are prescribed to them. Satisfaction is a complex matter to describe, since it involves fulfillment of expectations, convenience of use, and measurable positive results [2].

Adherence has been defined by the World Health Organization (WHO) as the extent to which a person's behavior-taking medication, following a diet, and/or executing lifestyle changes-corresponds with agreed recommendations from a healthcare provider [3]. A meta-analysis of adherence studies across many therapeutic areas found an average rate of adherence of $75 \%$ [4]. However, the WHO estimates an average adherence rate of $50 \%$ among chronically ill patients in the developed world [3].

Despite the apparent benefits of DMD use, rates of adherence are often variable and in some cases are quite low. Rates of medication drop-out or loss to follow-up during clinical trials, though typically below $10 \%$, have reached as high as $33.9 \%[5,6]$.

Although DMDs for MS patients are of benefit, some problems are associated with their use, including inconvenient modes and schedules of administration, long periods of therapy, and significant side effects. Moreover, DMD use is complicated by the unpredictability of MS disease course and the fact that DMDs do not provide direct relief of ongoing MS-related symptoms. Therefore, DMD use may affect an individual's adherence to therapy [7-9].

Patient's treatment satisfaction is an important tool for making health decisions related to adherence and continuation of treatment. Treatment satisfaction has been linked to adherence level as an expression of the quality of provided care, as satisfied patients are more likely to adhere better to their medications [10-12].

Since reports about medication adherence and satisfaction in patients with MS in Arab countries are lacking, the current study aimed to assess medication adherence and its relationship with treatment satisfaction of MS patients in the Kingdom of Saudi Arabia.

\section{Patients and methods}

This study followed a cross-sectional research design. MS patients were recruited from outpatient clinics of all tertiary care hospitals $(N=10)$ in all regions of Saudi Arabia (i.e., southern, eastern, western, middle, and northern regions). A total of 598 adult (aged 18 years or more) patients with the diagnosis of MS according to McDonald Criteria [13] registered at tertiary care hospitals in Saudi Arabia could be included.

Patients' medication adherence was assessed using the Arabic version of the eight-item Morisky Medication Adherence Scale (MMAS-8) [14-16]. This version is a well-validated instrument [17]. The total score of the scale ranges from 0 to 8 , with higher scores reflecting higher adherence. A score of 8 denotes high adherence scores from 6 to 7 which denote moderate adherence, while scores $<6$ denote low adherence [18].

Our patients who had low or moderate adherence scores were classified as "|non-adherent," while those with a score of 8 were classified as "adherent."

Treatment satisfaction was assessed using the 25-item Treatment Satisfaction Questionnaire for Medication. Responses were scored from 1 to 5 on a Likert scale, where (1) indicates "I do not agree at all," (2) indicates "I tend to disagree," (3) indicates "I have no opinion," (4) indicates "I tend to agree," and (5) indicates "I totally agree." Questions comprise four aspects representing the personal impressions of treatment benefit, tolerability, convenience of use, and general satisfaction with the treatment [2].

Treatment benefit of the drug was examined in terms of patient's general perception of whether the drug had the effect that it was supposed to have (for example, control of relapses). Tolerability of the drug was assessed in terms of its adverse events and interference with social and professional life and whether side effects from that particular DMD were acceptable as part of the treatment. Convenience of the drug was evaluated in terms of its ease of storage and use and also whether it could be transported if necessary (for example, for use during trips). General satisfaction with treatment was evaluated in terms of the positive and negative aspects of quality of life since treatment with that particular DMD had started [14]. Scores obtained were summed and the percentage of satisfaction score was calculated, where higher scores indicated higher satisfaction. Moreover, there was an additional question in which the patients were invited to make any comments that they considered relevant. The responses to this question were not considered in the score. 
Severity of disease was assessed using the Patient-Determined Disease Steps (PDDS). Scores range from 0 (normal) to 8(bed-ridden) [15]. It is a valid patient-reported outcome of disability in MS [19]. Moreover, the study questionnaire included participants' socio-demographic data, including gender, age, level of education, region, and marital status of the participants.

\section{Statistical analysis}

The Statistical Package for Social Sciences (SPSS Inc, Chicago, IL, USA) version 21 was used for the statistical analysis of the data. Descriptive statistics were performed to assess the socio-demographic variables and medication use in the study population. Continuous variables were presented as mean $\pm \mathrm{SD}$. Independent $t$ test and ANOVA test were used to examine the association between continuous variables (when the assumption are not valid, we used the nonparametric Mann-Whitney test and Kruskal Wallis test), while chi-square test was used to identify the associations between categorical variables. In all tests, $p \leq 0.05$ was considered as statistically significant.

Table 1 Socio-demographic and clinical characteristics of MS patients according to their medication adherence $(n=598)$

\begin{tabular}{|c|c|c|c|c|}
\hline Characteristics & Total $(n=598)$ & Adherent $(n=58,9.7 \%)$ & Non-adherent $(n=548,90.3 \%)$ & $p$ value \\
\hline Region & & & & $0.096^{a}$ \\
\hline Southern & $170(28.4 \%)$ & $20(11.8 \%)$ & $150(88.2 \%)$ & \\
\hline Middle & $150(25.1 \%)$ & $20(13.3 \%)$ & $130(86.7 \%)$ & \\
\hline East & $114(19.1 \%)$ & $8(7.0 \%)$ & $106(93.0 \%)$ & \\
\hline North & $28(4.7 \%)$ & 0.0 & $28(100.0 \%)$ & \\
\hline West & $136(22.7 \%)$ & $10(7.4 \%)$ & $126(92.6 \%)$ & \\
\hline Gender & & & & $0.720^{\mathrm{a}}$ \\
\hline Male & $214(35.8 \%)$ & $22(10.3 \%)$ & $192(89.7 \%)$ & \\
\hline Female & $384(64.2 \%)$ & $36(9.4 \%)$ & $348(90.6 \%)$ & \\
\hline Age in years, mean \pm SD (range) & $32.4 \pm 8.5(15-60)$ & $33.5 \pm 9.9(15-56)$ & $32.3 \pm 8.3(15-60)$ & $0.323^{b}$ \\
\hline Marital status & & & & $0.597^{\mathrm{a}}$ \\
\hline Single & $250(41.8 \%)$ & $24(9.6 \%)$ & $226(90.4 \%)$ & \\
\hline Married & $310(51.8 \%)$ & $34(11.0 \%)$ & $276(89.0 \%)$ & \\
\hline Divorced & $36(6.0 \%)$ & 0.0 & $36(100.0 \%)$ & \\
\hline Widower & $2(0.4 \%)$ & 0.0 & $2(100.0 \%)$ & \\
\hline Educational level & & & & $<0.001^{a}$ \\
\hline Illiterate & $4(0.7 \%)$ & $2(50.0 \%)$ & $2(50.0 \%)$ & \\
\hline Primary & $12(2.0 \%)$ & $2(16.7 \%)$ & $10(83.3 \%)$ & \\
\hline Intermediate & $28(4.7 \%)$ & $12(42.9 \%)$ & $16(57.1 \%)$ & \\
\hline Secondary & $140(23.4 \%)$ & $4(2.9 \%)$ & $136(97.1 \%)$ & \\
\hline University & $414(69.2 \%)$ & $38(9.2 \%)$ & $376(90.8 \%)$ & \\
\hline Age at disease onset mean \pm SD (range) & $25.9 \pm 7.9(13-56)$ & $27.3 \pm 10.4(14-51)$ & $25.7 \pm 7.6(13-56)$ & 0.136 \\
\hline Disease duration in years (mean \pm SD) & $6.6 \pm 4.8$ & $6.1 \pm 4.5$ & $6.6 \pm 4.8$ & $0.476^{\mathrm{b}}$ \\
\hline No. of hospital admissions, mean \pm SD & $1.4 \pm 1.7$ & $1.1 \pm 1.4$ & $1.4 \pm 1.7$ & $0.139^{b}$ \\
\hline No. of attacks during last 2 years, mean \pm SD (range) & $1.4 \pm 1.9(0-14)$ & $1.5 \pm 1.0(0-4)$ & $1.9 \pm 2.0(0-14)$ & $0.118^{\mathrm{b}}$ \\
\hline Currently used disease-modifying therapies ${ }^{c}$ & & & & $0.032^{\mathrm{a}}$ \\
\hline Interferon beta-1b (SC) & $144(24.1)$ & $14(9.7)$ & $130(90.3)$ & \\
\hline Interferon beta-1a (SC) & $112(18.7)$ & $8(7.1)$ & $104(92.9)$ & \\
\hline Interferon beta-1a (IM) & $100(16.7)$ & $12(12.0)$ & $88(88.0)$ & \\
\hline Fingolimod (PO) & $104(17.4)$ & $18(17.3)$ & $86(82.7)$ & \\
\hline Others & $90(15.4)$ & $4(4.4)$ & $86(95.6)$ & \\
\hline PDDS (mean \pm SD) & $2.8 \pm 1.9$ & $3.1 \pm 2.3$ & $2.8 \pm 2.00$ & $0.219^{b}$ \\
\hline
\end{tabular}

$X^{2}$ test

${ }^{\mathrm{b}}$ Mann-Whitney test

${ }^{\mathrm{c}} 48$ cases were not using any medication 


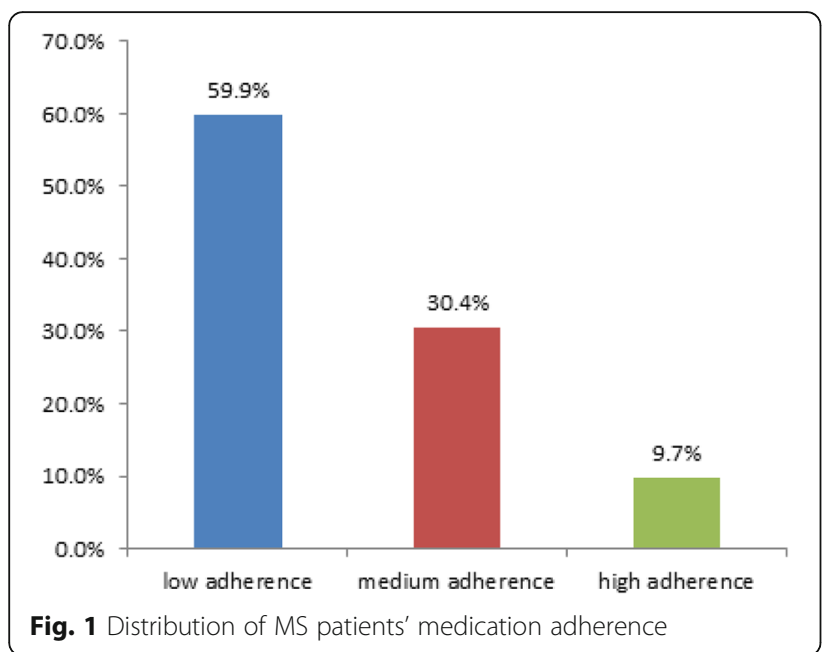

\section{Results}

Participants' characteristics are presented in Table 1. Almost two thirds were females (64.2\%), 51.8\% were married, $69.2 \%$ were university graduates, and more than half of participants were from the southern and middle regions (28.4\% and $25.1 \%$, respectively). Participants' mean age was $32.4 \pm 8.4$ years, (range 15 to 60 years), their mean age at disease onset was $25.9 \pm 7.6$ years, and their mean disease duration was $6.6 \pm 4.8$ years. The mean number of patients' hospital admissions was $1.4 \pm 1.7$, while their mean number of attacks during the last 2 years was $1.4 \pm .9$. The most currently used drug was interferon beta-1b (144, 24.1\%), while 112 patients (18.7\%) were using interferon beta-1a, 104 patients (17.4\%) were using fingolimod, and the remaining were on other DMDs

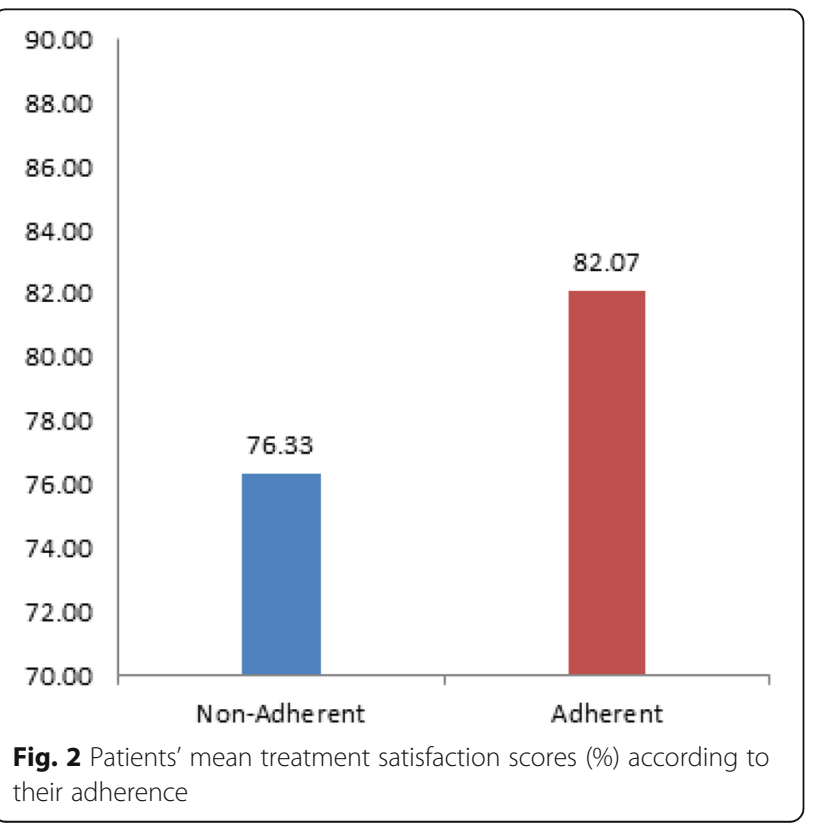

as shown in Table 1 while 48 cases were not using any medication. Patients' mean PDDS was $2.8 \pm 1$ 1.9.

According to patients' MMAS-8, 59.9\% with low adherence $(3.6 \pm 1.57)$, 30.4\% moderate adherence $(6.82 \pm 0.45)$, and $9.7 \%$ high adherence, as shown in Fig. 1. Based on these findings, 9.7\% of our MS patients were "adherent" while $90.3 \%$ were "nonadherent."

Patients' adherence to their medication differed significantly according to their educational level $(p<0.001)$, with a tendency toward more adherence with higher levels of education (i.e., secondary or university levels) than lower educational levels (i.e., illiterate, primary, or intermediate levels). Moreover, patients' adherence differed significantly according to their currently received medications $(p=0.032)$, with those on fingolimod capsules having the highest adherence (17.3\%), followed by beta interferons, i.e., interferon beta-1a intramuscular, which is injected intramuscularly, as well as interferon beta- $1 \mathrm{~b}$ and interferon beta-1a, which are injected subcutaneously. However, patients' medication adherence did not differ significantly according to their other studied characteristics (i.e., age, gender, region, marital status, age at disease onset, duration of disease, number of hospital admissions, number of attacks within the last 2 years, duration of used medications in years, or disease severity, Table 1).

The mean treatment satisfaction percent score for adherent patients was significantly higher than that of nonadherent patients $(82.07 \pm 8.10 \%$ and $76.33 \pm 12.27 \%$, respectively, $p=0.001$ ), as shown in Fig. 2 .

Figure 3 shows that the main two reasons stated by MS patients for changing their prescribed drugs were the presence of attacks, i.e., response to treatment was substandard (41.8\%) and the experienced side effects of used drugs (39.9\%).

For currently used drugs, Table 2 shows that mean percent scores of treatment satisfaction were higher among adherent patients than non-adherent patients. However, differences in expressed satisfaction mean percent scores according to adherence among MS patients were statistically significant among those receiving interferon beta- $1 \mathrm{~b}$ and interferon beta-1a intramuscular ( $p=0.023$ and $p=0.049$, respectively). On the other hand, PDDS mean score differed significantly according to patients' treatment adherence only among those receiving interferon beta-1b, with higher mean severity score among those who were adherent $(p=0.002)$.

\section{Discussion}

Medications' efficacy and safety are usually central considerations in the choice of therapy for MS patients. However, with a recent increase in the number of available treatments, other outcomes, such as 


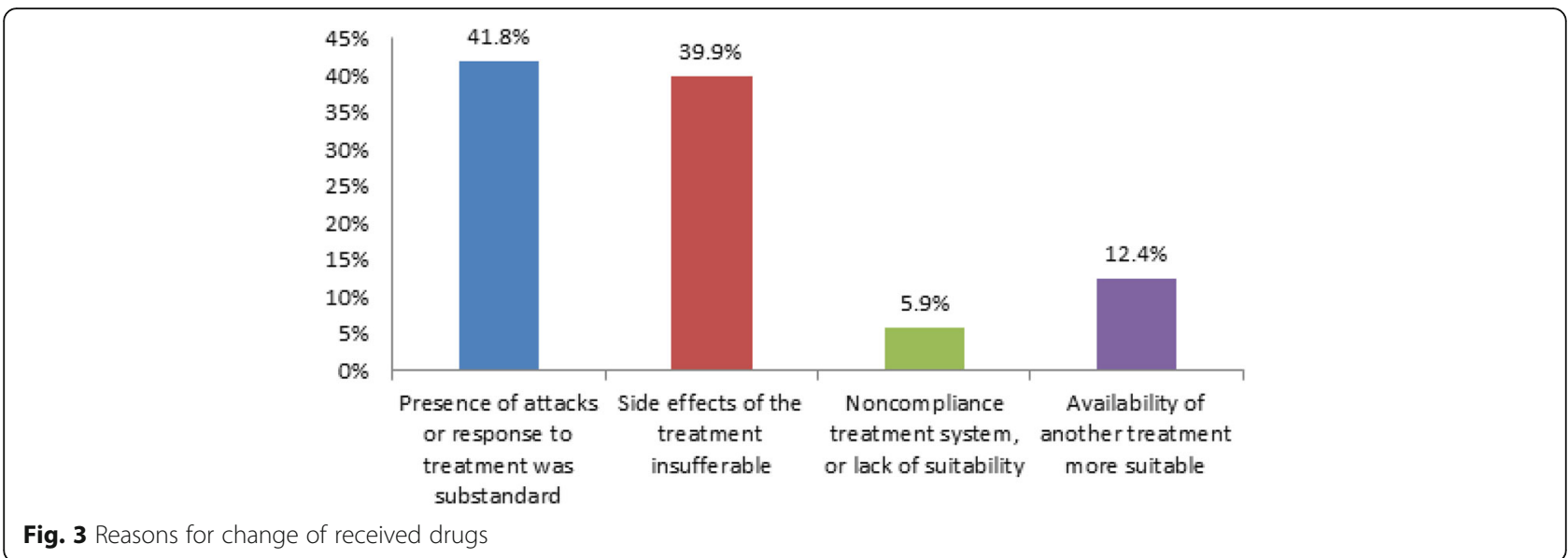

patients' experience, adherence, and satisfaction with received treatment have become increasingly important. Non-adherence of MS patients to the prescribed disease-modifying therapies is associated with reduced efficacy [20].

Regarding medication adherence of MS patients, the present study showed a low rate among MS patients (9.7\%). Our patients' adherence to their medication differed significantly with their educational level, with less tendency to be adherent among those with higher levels of education. In addition, patients' adherence differed significantly according to their currently received DMD, with those on fingolimod capsules having the highest adherence (17.3\%), followed by those receiving beta-interferons injections, i.e., interferon beta-1a intramuscular (12\%), interferon beta-1b (9.7\%), and interferon beta-1a (7.1\%).

The low rate of medication adherence among MS patients has been also noted by Haase et al. [21], who stated that several studies on MS patients confirm low rates of medication adherence. Hansen et al. [22] found that $30-40 \%$ of MS patients were adherent to their treatment over a period of 2 years. However, higher medication adherence rates were reported by Menzinet al. among MS patients, which ranged from 41 to $88 \%$ [23].
Decoo and Vokaer stated that the main strategies to improve treatment adherence among MS include patients' contact with health care providers and using modern practical aids, such as alert systems (e.g., text messages, smartphone applications), calendars, diaries, brochures, treatment timetables, medication cards, and information brochures; improving patient awareness regarding the disease and its treatment; and enforcing the role of family members to help improve patients' treatment adherence [24].

The wide variability in reported medication adherence among MS patients may be explained by differences in its definition. In the present study, we followed a dichotomous classification for our patients, where we considered MS patients who scored 8 in the Morisky Medication Adherence Scale as "adherent," while all those with lower scores as "non-adherent."

Halpern et al. [25] found higher adherence rates among patients receiving interferon- $\beta 1$ a (IM) administered once a week (69.4\%), and interferon- $\beta 1$ a administered subcutaneously every other day $(63.8 \%)$ than for interferon- $\beta 1 \mathrm{~b}$ administered subcutaneously three times a week (58.4\%). Moreover, Becker et al. [26] noted that most MS patients would choose oral over injectable treatments.

Table 2 Mean scores for MS patients' treatment satisfaction and PDDS according to their adherence to currently used drugs

\begin{tabular}{|c|c|c|c|c|c|c|c|c|c|c|c|}
\hline & & \multicolumn{2}{|c|}{ INF beta-1b S/Q } & \multicolumn{2}{|l|}{ INF beta-1a S/Q } & \multicolumn{2}{|l|}{ INF beta-1a IM } & \multicolumn{2}{|l|}{ Fingolimod } & \multicolumn{2}{|l|}{ Others } \\
\hline & & $\begin{array}{l}\text { Non- } \\
\text { adherent }\end{array}$ & $\overline{\text { Adherent }}$ & Non-adherent & $\overline{\text { Adherent }}$ & Non-adherent & Adherent & Non-adherent & $\overline{\text { Adherent }}$ & Non-adherent & $\overline{\text { Adherent }}$ \\
\hline \multirow{3}{*}{$\begin{array}{l}\text { Treatment } \\
\text { satisfaction }\end{array}$} & Mean & 75.25 & 83.14 & 76.04 & 83.25 & 75.82 & 81.83 & 81.16 & 81.33 & 78.53 & 84.50 \\
\hline & SD & 12.52 & 7.24 & 10.47 & 9.30 & 10.18 & 6.37 & 11.73 & 10.00 & 11.59 & 5.20 \\
\hline & $p$ & 0.023 & & 0.078 & & 0.049 & & 0.954 & & 0.310 & \\
\hline \multirow[t]{3}{*}{ PDDS } & Mean & 2.3 & 3.9 & 2.9 & 4.0 & 2.4 & 1.3 & 2.7 & 3.4 & 3.7 & 3.0 \\
\hline & SD & 1.7 & 2.2 & 1.7 & 2.4 & 1.9 & 0.8 & 2.0 & 2.3 & 2.5 & 2.3 \\
\hline & $p$ & 0.002 & & 0.109 & & 0.067 & & 0.573 & & 0.182 & \\
\hline
\end{tabular}


Haase et al. [21] found a numerically greater risk of disease relapse or progression among non-adherent MS patients compared with those categorized as adherent patients, with findings statistically significant in two out of four analyzed studies.

Cascione et al. [27] stated that patient retention rate with fingolimod was significantly higher after 1 year than with injectable disease-modifying therapies in MS patients ( $81 \%$ vs. $29 \%$, respectively). Compared to injectable DMDs, fingolimod also improved clinical and radiographic outcomes and was associated with greater patient satisfaction. Cohen and Rieckmann [27] noted that while injectable disease-modifying therapies typically are used as first-line therapies for MS, research suggests the requirement for injections may reduce patient adherence. However, Wissemann et al. [28] reported no statistically significant differences regarding MS patients' adherence according to their gender, age, or route of DMD administration.

The main underlying reasons stated by our patients for changing their prescribed drugs were the presence of attacks, substandard response to treatment, or suffering the side effects of used drugs. The mean treatment satisfaction score among MS patients with medication adherence was significantly higher than that of non-adherent patients. Differences in expressed treatment satisfaction according to treatment adherence among MS patients were statistically significant among those receiving interferon beta- $1 \mathrm{~b}$ and interferon beta- $1 \mathrm{a}$ intramuscular, while PDDS mean scores differed significantly according to patients' treatment adherence among those receiving beta interferon.

These findings are in accordance with those reported by several studies, which showed that adherent patients usually report greater satisfaction with their received medications regarding convenience and effectiveness $[9,29,30]$.

Vrijens et al. [31] noted that, with increasing disease duration, patients' adherence to their medications usually decreases. In addition, the lack of patients' understanding for the need of long-term therapy, and also experienced side effects, plays an important role [32, 33]. Moreover, the results of a meta-analysis confirmed that patients who perceive higher disease severity are more likely to be adherent to their treatment [4].

In conclusion, medication adherence among MS patients in Saudi Arabia is very low. Higher adherence is significantly associated with patients' higher levels of education and their received DMD, with those on fingolimod capsules having the highest adherence, followed by those receiving beta-interferon injections. The main underlying reasons for changing prescribed drugs are the presence of attacks, substandard response to treatment, or suffering the DMDs' side effects. Medication adherence is associated with higher treatment satisfaction, especially among those receiving interferon beta- $1 \mathrm{~b}$ and interferon beta-1a intramuscular. Moreover, medication adherence was positively associated with higher severity among patients receiving beta interferon.

Therefore, it is recommended that treatment adherence of MS patients should be improved through raising patients' awareness regarding their disease and its treatment, more contact with health care providers, using of practical aids to urge them to adhere to their medication, and to enforce the role of patients' family members to improve patients' adherence.

\section{Abbreviations}

DMD: Disease-modifying drugs; MMAS-8: Morisky Medication Adherence Scale; MS: Multiple sclerosis; PDDS: Patient Determined Disease Steps; WHO: World Health Organization

\section{Acknowledgements}

Not applicable.

\section{Authors' contributions}

AA and MA contributed to the methodology, data collection, analysis, writing, and reviewing of the manuscript. MAt, NA, and LS contributed to the methodology, data collection, analysis, and writing of the manuscript. SA contributed to the methodology, data collection, and analysis of the manuscript. MAm contributed to the methodology, data collection, analysis, writing, and reviewing of the manuscript, All authors read and approved the final manuscript.

\section{Funding}

Not applicable.

\section{Availability of data and materials}

Availability of data can be available upon reasonable request.

\section{Ethics approval and consent to participate}

The ethical approval for conducting this study was obtained from the Head of Research Ethics Committee (HA-06-B-001) in King Khalid University (REC) \# 2016-08-23). The informed consent of participants was obtained prior to their participation in this study.

Consent for publication

Not applicable.

\section{Competing interests}

The authors declare that they have no competing interests.

\section{Author details}

${ }^{1}$ Neurology Section, Department of Medicine, King Saud University, P.O. Box 641, Riyadh, Saudi Arabia. ${ }^{2}$ Armed Forces Hospitals Southern Region Saudi Arabia, Khamis Mushayt, Saudi Arabia. ${ }^{3}$ King Abdulaziz Medical City, NGHA, Riyadh, Saudi Arabia. ${ }^{4}$ Neurology, College of Medicine, King Khalid University, Abha, Saudi Arabia.

Received: 4 February 2019 Accepted: 30 June 2019

Published online: 28 August 2019

\section{References}

1. Campbell JD, Ghushchyan V, McQueen RB, et al. Burden of multiple sclerosis on direct, indirect costs and quality of life: national US estimates. Mult Scler Relat Disord. 2014;3(2):227-36.

2. Spessotto CV, Cavalli H, Eboni ACB, Machado RB, Mousquer AM, Palazzo LB, et al. Patients' satisfaction with and views about treatment with diseasemodifying drugs in multiple sclerosis. Arq Neuropsiquiatr. 2016;74(8):617-20.

3. World Health Organization. Adherence to long-term therapies: evidence for action. Geneva: World Health Organization; 2003. 
4. DiMatteo MR. Variations in patients' adherence to medical recommendations: a quantitative review of 50 years of research. Med Care. 2004; $42: 200-9$

5. Remington $G$, Rodriguez $Y$, Logan D, Williamson C, Treadaway K. Facilitating medication adherence in patients with multiple sclerosis. Int J MS Care. 2013;15(1):36-45.

6. Mohr DC, Goodkin DE, Masuoka L, Dick LP, Russo D, Eckhardt J, Boudewyn $A C$, Bedell $L$. Treatment adherence and patient retention in the first year of a phase-III clinical trial for the treatment of multiple sclerosis. Mult Scler J. 1999:5(3):192-7.

7. Hadjimichael $\mathrm{O}$, Volmer TL. Adherence to injection therapy in multiple sclerosis: patients survey. Neurology. 1999;53:1190-7.

8. Klauer T, Zettl UK. Compliance, adherence, and the treatment of multiple sclerosis. Journal of Neurology. 2008;255:87-92.

9. TworkS NI, Scherer P, Haas J, Pohlau D, Kugler J. Immunomodulating drugs in multiple sclerosis: compliance, satisfaction and adverse effects evaluation in a German multiple sclerosis population. Curr Med Res Opin. 2007;23: 1209-15.

10. Zyoud SH, Al-Jabi SW, Sweileh WM, Morisky DE. Relationship of treatment satisfaction to medication adherence: findings from a cross-sectional survey among hypertensive patients in Palestine. Health Qual Life Outcomes. 2013; 11:191.

11. Revicki DA. Patient assessment of treatment satisfaction: methods and practical issues. Gut. 2004;53:iv40-4.

12. Biderman A, Noff E, Harris SB, Friedman N, Levy A. Treatment satisfaction of diabetic patients: what are the contributing factors? Fam Pract. 2009;26:102-8.

13. Polman $\mathrm{CH}$, et al. Diagnostic criteria for multiple sclerosis: 2010 revisions to the Mcdonalds criteria. Ann Neurol. 2011.

14. Morisky DE, Ang A, Krousel-Wood M, Ward HJ. Predictive validity of a medication adherence measure in an outpatient setting. J ClinHypertens (Greenwich). 2008;10:348-54.

15. Vollmer TI, Ni W, Stanton S, Hadjimichael O. The NARCOMS patient registry: a resource for investigators. Int J MS Care. 1999;1:12-15.

16. Ashur ST, Shamsuddin K, Shah SA, Bosseri S, Morisky DE. Reliability and known-group validity of the Arabic version of the 8-item Morisky Medication Adherence Scale among type 2 diabetes mellitus patients. East Mediterr Health J. 2015;21(10):722-8.

17. Aljumah K, Hassali AA, AIQhatani S. Examining the relationship between adherence and satisfaction with antidepressant treatment. Neuropsychiatr Dis Treat. 2014;10:1433-8.

18. Learmonth YC, Motl RW, Sandroff BM, Pula JH, Cadavid D. Validation of patient determined disease steps (PDDS) scale scores in persons with multiple sclerosis. BMC Neurology. 2013;13:37.

19. FernaÂndez O, Duran E, Ayuso T, HernaÂndez L, Bonaventura I, Forner M, et al. Treatment satisfaction with injectable disease-modifying therapies in patients with relapsing - remitting multiple sclerosis (the STICK study). PLoS ONE. 2017;12(10):e0185766.

20. Haase R, Kullmann JS, Ziemssen T. Therapy satisfaction and adherence in patients with relapsing-remitting multiple sclerosis: the THEPA-MS survey. Therapeutic Advances in Neurological Disorders. 2016;9(4):250-63.

21. Hansen K, Schüssel K, Kieble M, Werning J, Schulz M, Friis R, et al. Adherence to disease modifying drugs among patients with multiple sclerosis in Germany: a retrospective cohort study. PLoS One. 2015;10(7):e0133279.

22. Menzin J, Caon C, Nichols C, White L, Friedman M, Pill M. Narrative review of the literature on adherence to disease-modifying therapies among patients with multiple sclerosis. J Manag Care Pharm. 2013;19:S24-40.

23. Decoo D, Vokaer M. Treatment adherence in multiple sclerosis: a survey of Belgian neurologists. Patient Prefer Adherence. 2015;9:1669-76.

24. Halpern R, Agarwal S, Dembek C, Borton L, Lopez-Bresnahan M. Comparison of adherence and persistence among multiple sclerosis patients treated with disease-modifying therapies: a retrospective administrative claims analysis. Patient Prefer Adherence. 2011;5:73-84.

25. Becker V, Heeschen V, Schuh K, Schieb H, Ziemssen T. Patient satisfaction and healthcare services in specialized multiple sclerosis centres in Germany. Ther Adv Neurol Disord. 2018;11:1756285617748845.

26. Cascione M, Cree B, Wynn D, et al., on behalf of the PREFERMS investigators, Key results from PREFERMS: real-world patient retention and outcomes on fingolimod versus platform injectable disease-modifying therapies in early relapsing-remitting multiple sclerosis; Abstract [4148]; Poster [DX47] presentation at 2016 Annual Meeting of the Consortium of Multiple Sclerosis (CMSC) in National Harbor, Md. 2016.
27. Cohen BA, Rieckmann P. Emerging oral therapies for multiple sclerosis. Int J Clin Pract. 2007;61:1922-30.

28. Wissemann K, Gudesblatt M, Bumstead B, Zarif M, Fafard L, Thotam S, et al. Multiple sclerosis: population analysis of predicted nedication adherence behavior by Morisky Medication Adherence Scale (MMAS-8). Neurology. 2016;86(16 Supplement):P2.132.

29. Saiz A, Mora S, Blanco J. Therapeutic compliance of first line diseasemodifying therapies in patients with multiple sclerosis. Compliance study. Neurologia. 2015;30:214-22.

30. Vrijens B, Vincze G, Kristanto P, Urquhart J, Burnier M. Adherence to prescribed antihypertensive drug treatments: Iongitudinal study of electronically compiled dosing histories. BMJ. 2008;336:1114-7.

31. Osterberg L, Blaschke T. Adherence to medication. N Engl J Med. 2005; 353:487-97

32. Horne R. Compliance, adherence, and concordance: implications for asthma treatment. Chest. 2006;130:65S-72S.

33. Ho P, Bryson C, Rumsfeld J. Medication adherence. Circulation. 2009;119: 3028-35.

\section{Publisher's Note}

Springer Nature remains neutral with regard to jurisdictional claims in published maps and institutional affiliations.

\section{Submit your manuscript to a SpringerOpen ${ }^{\circ}$ journal and benefit from:}

- Convenient online submission

- Rigorous peer review

- Open access: articles freely available online

- High visibility within the field

- Retaining the copyright to your article

Submit your next manuscript at $\boldsymbol{\nabla}$ springeropen.com 